\title{
Triküspit Kalp Kapakçıklarının Üç Boyutlu (3B) Biyobaskı Metotları ile Fabrikasyonu
}

\author{
Ali AKPEK ${ }^{* 1}$ \\ ${ }^{1}$ Gebze Teknik Üniversitesi, Mühendislik Fakültesi, Biyomühendislik Bölümü, 41400, Kocaeli
}

(Alınıș / Received: 31.12.2016, Kabul / Accepted: 07.09.2017, Online Yayınlanma / Published Online: 27.10.2017)

\begin{abstract}
Anahtar Kelimeler
3B biyoyazıcl,

Triküspit kalp kapakçı̆̆ı,

Biyomalzeme
\end{abstract}

\begin{abstract}
Özet: Geçen yllar içerisinde organ transplantasyonu konusunda olan ihtiyaç sürekli olarak artmıştır. Organ naklinin kendisini bir ihtiyaç olarak en çok belli ettiği alanlardan bir tanesi de kalp kapakçı̆̆ı hastalıklarıdır. Bu sebepler dolayısıyla biyoyazıcılar aracılı̆̆ı ile yüksek biyouyumluluğa sahip yapay kalp kapakçıkları üretmek mecburidir. Bu çalışmada amaçlanan, kalp kapakçıkları hastalıklarında kullanılmak üzere stereolitografi yöntemi ile triküspit bir kalp kapakçığı üretmektir. Bu çalışmada stereolitografi yöntemi ile yüksek çözünürlülüğe sahip triküspit bir kalp kapakçı̆̆ı üretilmeye çalışılmış ve temel biyouyumluluk özellikleri incelenmiștir. Sonuç itibari ile aortik bir köke sahip olan triküspit kalp kapakçıkları çeşitli biyomalzemeler aracılığı ile üretilmiştir. Çalışma henüz klinik amaçlarla kullanılmak için çok erken olsa dahi stereolitografinin biyoyazıcı olarak kullanılır olduğunu göstermesi açısından önemlidir.
\end{abstract}

\section{Fabrication of Tricuspid Heart Valves by 3D Bioprinting Techniques}

\section{Keywords}

3D bioprinting,

Tricuspid heart valve, Biomaterials

\begin{abstract}
Over the past several decades, there has been an ever-increasing demand for organ transplants. Organ donation emerges as the most feasible solution especially in heart valve diseases. Due to these reasons, growing or fabricating heart valves using bioprinting techniques with high biocompatability is an obligatory. The purpose of this study is; fabricating 3D artificial tricuspid heart valves by stereolithography that has potential to be obtained for heart valve replacements. In this study, a tricuspid heart valve is tried to be fabricated by stereolithography with high resolution and the biocompatibility characteristics is analyzed. As a result, a tricuspid heart valve which has an aortic root has been fabricated with various biomaterials. It is still early to use these results for clincal purposes but the study is still important since it presents the possible applications of stereolithography for bioprinting.
\end{abstract}

\section{Giriş}

Geçen yllar içerisinde organ transplantasyonu konusunda olan ihtiyaç sürekli olarak artmıştır. Organ nakline ihtiyaç sürekli olarak artarken organ bağışı sayısında ciddi bir artış gözlenmemiştir.

$\mathrm{Bu}$ sebeple her sene yüzbinlerce insan organ nakli için sırada beklerken hayatlarını kaybetmektedir ve bu sayı her yıl artmaktadır. Bu durum Şekil 1'de gösterilmiştir [1]. Organ naklinin kendisini bir ihtiyaç olarak en çok belli ettiği alanlardan bir tanesi de kalp kapakçığı hastalıklarıdır. Kalp kapakçığı hastalıkları halen dünya üzerindeki en büyük ölüm nedenlerinden bir tanesi durumundadır [2]. Her yıl 290,000'den fazla hasta kalp kapakcığı ameliyatı geçirmektedir. Bu sayının 2050 yılına kadar yılda 850,000 'e ulaşacağı tahmin edilmektedir $[3,4]$.
Kalp kapakçı̆̆ı hastalıklarının tedavisi amacıyla iki tür yapay kalp kapakcığı kullanılmaktadır. Birincisi mekanik yapay kalp kapakçıkları diğeri ise biyoprostetik yapay kalp kapakçıklarıdır [5]. Bu iki yapay kalp kapakçı̆̆ının da en büyük dezavantajı; nakledilmelerinden sonra vücut içerisinde hastanın gelişimi ile birlikte gelişmesine imkan bulunmamasıdır. $\mathrm{Bu}$ özellikle çocuklarda ciddi sorunlara sebebiyet vermektedir. Çocuklar büyüdükçe kalp kapakçıkları da büyümek zorundadır. Halbuki bu yapay kalp kapakçılkarının boyutları büyüyemediği için çocuklar her iki üç yılda bir tekrar ameliyat olmak ve kalp kapakçıklarını yeni bir modelle güncellemek zorunda kalmaktadırlar. Bunun yanında mekanik kalp kapakçıkları enfeksiyon, iltihap ve tromboz oluşumuna açık durumdadırlar. Benzer şekilde biyoprostetik kalp 
kapakçıkları da kireçlenme sebebiyle kalp kapakçıklarında kalınlaşmaya ve sertleşmeye bu nedenle de yetersiz kapanmaya ve böylelikle de sızıntıya neden olmaktadır [6].

Bütün bu sebepler dolayısıyla doku mühendisliği aracılığı ile kişinin kendi kök hücreleri kullanarak oluşturulabilen, biyouyumluluğu yüksek, nakledildikten sonra hasta ile birlikte gelişebilen ve diğer yapay kalp kapakçılarının sahip olduğu dezavantajlara sahip olmayan yapay kalp kapakçıkları üretilmeye çalışılması son derece önemli bir ihtiyaçtır. $\mathrm{Bu}$ araştırmanın motivasyonu bu özelliklere sahip bir yapay kalp kapakçığı üretebilmek ve kalp kapakçığı hastalıkları tedavisine yardımcı olmaya çalışmaktır.

$\mathrm{Bu}$ çalışmada amaçlanan, kalp kapakçıkları hastalıklarında kullanılmak üzere stereolitografi yöntemi ile üretilmiş yapay bir triküspit kalp kapakçı̆̆ı üretmektir. Günümüze kadar çesitli doku mühendisliği metodları ile üretilen değişik yapay kalp kapakçı̆̆ı modelleri incelendiğinde hayvan deneylerinde bir kaç aydan daha uzun süre işlevselliğini sürdürebilmiş bir model tespit edilememiștir. Bunun nedeni; üretilen bu yapay kalp kapakçıklarının biyomekanik özelliklerinin bir kaç aydan daha uzun süre kullanmak için yetersiz olmasıdır.

Stereolitografi yöntemi yüksek çözünürlüğe sahip son derece güçlü mekanik özelliklere sahip olan yapılar üretme konusunda bütün diğer $3 \mathrm{~B}$ baskı modellerinden önde olsa da biyoyazıcı olarak değerlendirilmemiştir. $\mathrm{Bu}$ çalışma da bunun başarılması sağlanmaya çalışılmıştır.

Stereolitografi ile üretilmiş yapay kalp kapakçıklarının hücre ekimi gerçekleştirilmiş ve sonrasında biyouyumluluk özellikleri karakterize edilmeye çalışılmıştır.

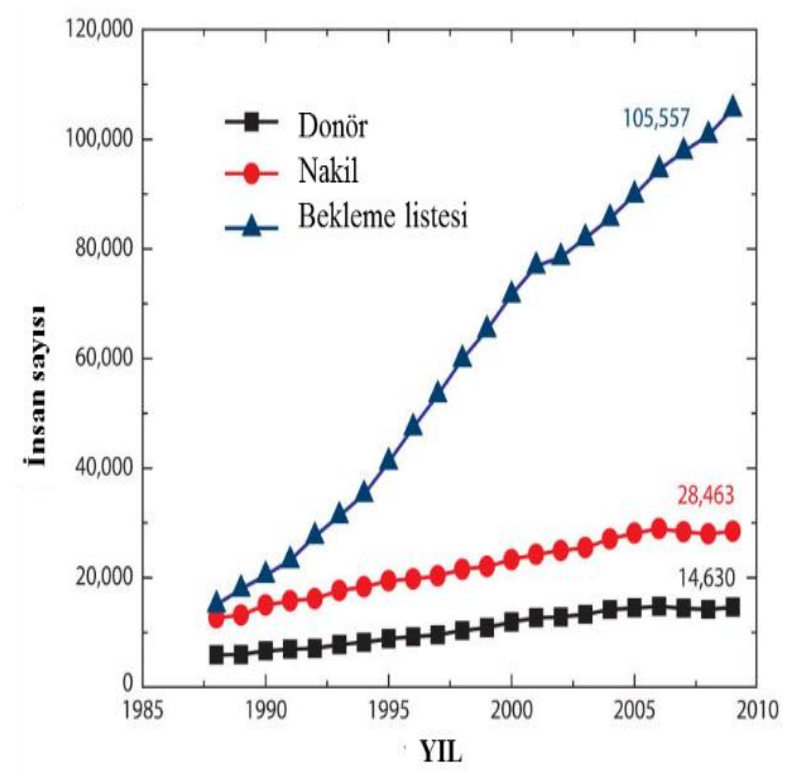

Şekil 1 Yıllara göre donör ve nakil listesi

\section{Materyal ve Metot}

\subsection{Materyal}

\subsubsection{PEGDA hazırlanması}

PEGDA (Polyethylene Glycol Diacrylate: Type A:Mn 700) Sigma-Aldrich şirketinden temin edildi ve hacimce $\quad 30 \%$ oranında sulandırıldı $0.5 \%$ fototetikleyici hazırlandı ve sulandırılmış PEGDA ile kullanıldı.

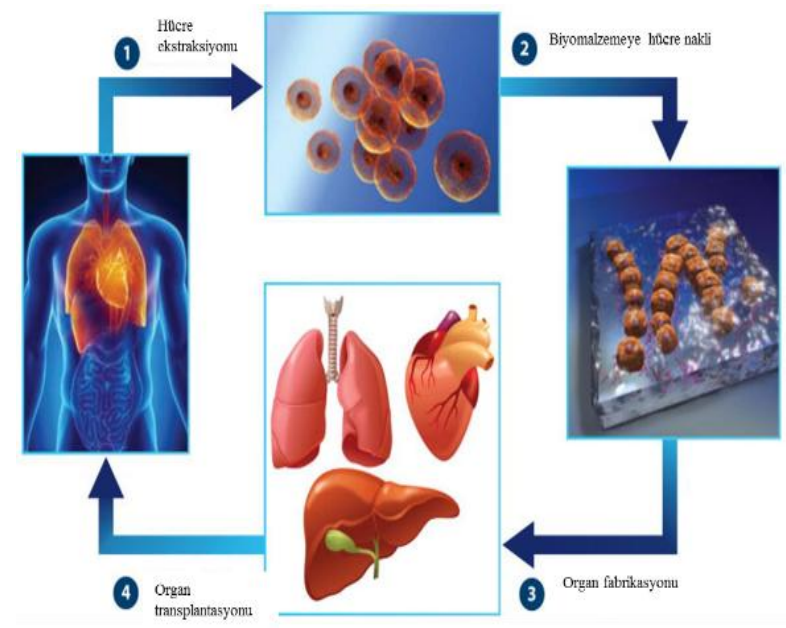

Şekil 2 Biyofabrikasyon süreci [7]

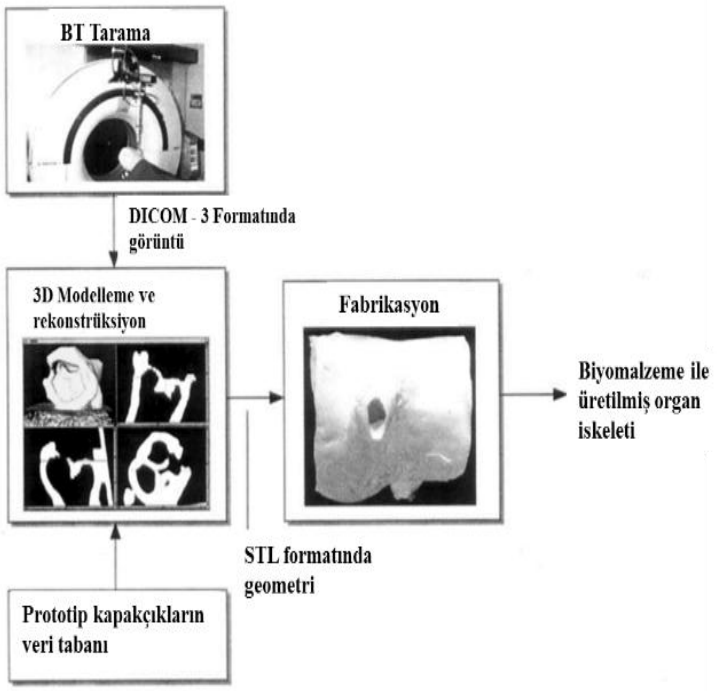

Şekil 3 Stereolitografi tekniğinin işlem süreci [8]

\subsubsection{B yazıcılar}

$\mathrm{Bu}$ çalışmada stereolitografi üretimini gerçekleştirmek için FormLabs Form 1+ üç boyutlu yazıcı kullanılmıştır. Bu teknoloji ile yazıcı başlığı sıvı reçine dolu bir rezervuarın içerisine daldırılmakta ve ağır ağır yukarı hareket ettirilerek katı bir üç boyutlu yapının ortaya çıkması sağlanmaktadır.

$\mathrm{Bu}$ modelde açık kaynak kodlu olarak elde edilen triküspit kalp kapakçığı modelleri stereolitografi ile üretilmeye uygun formata getirilmiş sonrasında ise tasarımlanan kalp kapakçıkları üretilerek bu yapıların üzerine hücre ekilmiştir. 


\subsubsection{Hücre kültürü}

Kardiyak fibroblast hücreleri DMEM, 10\% (v/v) FBS ile $5 \%$ CO2 atmosfer basincı altında $37^{\circ} \mathrm{C}$ ve $1 \%$ (v/v) $\mathrm{P} / \mathrm{S}$ ile kültür edilmiștir. Hücre ortamı uzun inkübasyon süreci nedeni ile her üç günde bir taze ortam ile değiştirilmiştir. Hücreler 70-80\% konfluens ile $\quad 0.25 \% \quad(\mathrm{w} / \mathrm{v})$ trypsin $/ 0.1 \% \quad(\mathrm{w} / \quad \mathrm{v})$ EDTA kullanılarak toplanmış ve deneyler için kullanılmıștır.

Stereolitografi ile kalp kapakçı̆̆ı üretilmiş ve bu kapakçık 1mm2'lik dilimlere ayrılarak 96'lık kuyu tipi petrilere yerleștirilmiştir. Sonrasında hücre kültürü gerçekleştirilmiş, trypsin ile muamele edildikten ve hücre ortamnda bir süre bekletildikten sonra 2$5 \times 106$ hücre mL-1 yoğunluğa ulaşması sağlanmıştır. Hücre çoğalması ve bağlanmasının temin edilebilmesi maksadı ile inkübatörde 2-3 gün bekletilmiştir.

\subsubsection{Hücre canlılığı testleri}

Stereolitografi ile üretilmiş olan kalp kapakçıklarına hücre ekimi gerçekleştirildikten sonra hücre canlılığı testleri gerçekleştirilmiştir.

Bunun için $2 \mu$ l Calcein ve $4 \mu$ l Ethidium Homodimer 1 ml PBS ile karıştırılmıştır. Daha önceden inkübatörde bekletilen $1 \mathrm{~mm} 2$ 'lik dilimlere ayrılmış üç adet kalp kapakçı̆̆ı parçası yeni bir petriye yerleştirilir ve kardiyak fibroblast hücreleri sistemden uzaklaştırılır. $\mathrm{Bu}$ parçacıklara $300 \mu \mathrm{l}$ Calcein ve Ethidium Homodimer karıştırışlmış PBS eklenmiştir. Bu yapılar 37으'de 20 dakika inkübe edilmiş ve sonra içinde karışım bulunan PBS sistemden uzaklaştırılmıştır. Son olarak kalp kapakçığı parçacıkları üçer defa PBS ile yıkanmıștır. Böylelikle mikroskop altında hücre canlılığının test edilmesi mümkün olmuştur. Bu test birinci gün, üçüncü gün ve yedinci günde tekrarlanmıştır. Her test için üç tane olmak üzere kalp kapakçığının toplam dokuz parçası kullanılmıștır.

\subsubsection{Mikroskop analizi}

Mikroskop görüntüleri Zeiss Axio Vert.A1 inverted mikroskop ve inverted Nikon Eclipse Ti mikroskop aracılığı ile elde edilmiştir. Mikroskopa bağlı bir CCD kamera görüntüleri kaydetmek için kullanılmıștır.

\subsection{Metot}

\subsubsection{Kalp kapakçığı tasarımları}

Şekil 3'te açıklandığı gibi BT görüntüsü stereolitografi amacı ile kullanılabilir. Ancak kalp kapakçıkları hastaları için yüksek çözünürlükte kalp kapakçığı görüntüsü elde etmek kolay değildir. Bu nedenle bu çalışmada hali hazırda üretilmiş olan 3D CAD kalp kapakçığı modelleri kullanılmıştır.

$\mathrm{Bu}$ çalışma esnasında triküspit kalp kapakçı̆̆ üretilmeye çalışılmıştır. Bu amaç için kullanılan model Şekil 4'te gösterilmiştir. Bu modelde aort damarı da kalp kapakçığına eklenmiştir. Bu modelde triküspit kalp kapakçı̆̆ının merkezinde bulunan ve kan akışının geçişini sağlayan boşluk belirgindir. $\mathrm{Bu}$ model gelecek çalışmalarda kalp kapakçığının gerek biyomekanik özelliklerini anlamamızda gerekse de akış dinamiklerini anlamamızda bize yardımcı olacaktır.

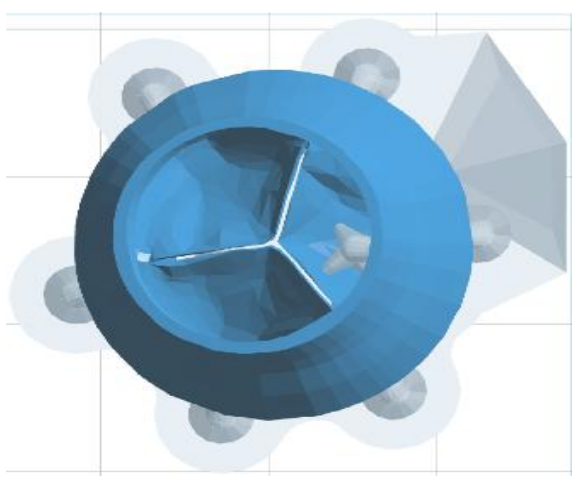

(a)

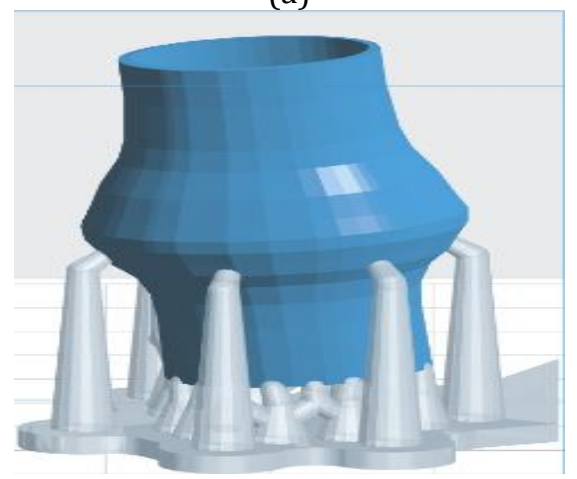

(b)

Şekil 4 Triküspit kalp kapakçığı, a) Yukarıdan b) Önden görünüş.

\subsubsection{B yazıcının biyo yazıcı olarak tasarımlanması}

Formlab Form 1+, üç boyutlu baskı işlemini gerçekleştirmek üzere tasarlanmıştır. $\mathrm{Bu}$ nedenle yazıcı başlığı ve rezervuar bu amaca uygun olarak tasarlanmıștır. Ancak biyobaskılama amacıyla kullanılacak biyomalzemeler oldukça pahalı ve üretilmesi güç olduğu için daha küçük bir rezervuar ve buna uygun daha küçük bir yazıcı başlığı tasarlamak şart olmuştur. Bu amaca uygun olarak tasarlanmış yazıcı başlığı ve rezervuar Şekil 5 ve 6.'da gösterilmiştir.

\section{Bulgular}

\subsection{PEGDA performansı}

Şekil 7a'da Şekil 4'te gösterilen triküspit kalp kapakçığı Formlabs Form 1+ 3D yazıcı tarafından PEGDA kullanılarak üretilmiștir. Șekil 7a'da üretilmiş olan yapay kalp kapakçığı yazıcı başlığına tutunmasına ve yapısal bütünlügünü korumasını sağlayan desteklerle birlikte fotoğraflanmıștır. $\mathrm{Bu}$ destekler Şekil 4'te gri parçalar olarak gösterilmiștir. 


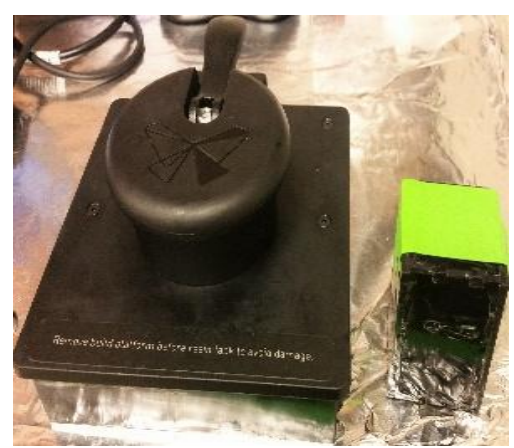

(a)

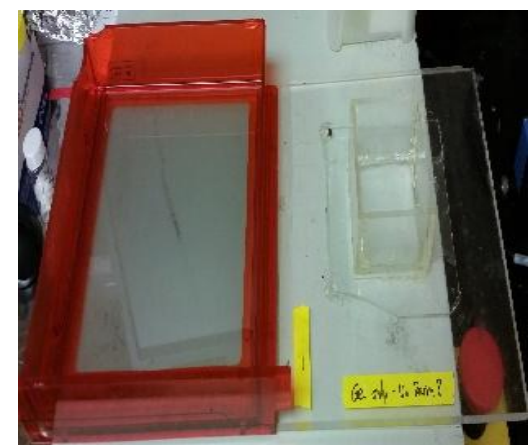

(b)

Şekil 5. a) Yazıcı başlıkları. Soldaki Formlabs 1+ orijinal yazıcı başlığı sağdaki ise biyo yazıcı olması için yeniden tasarlanmış yazıcı başlığı b) Reservuar. Soldaki orjinal Formlabs 1+ rezervuarı, sağdaki biyo yazıcı olarak kullanılacak yeniden tasarlanmış rezervuar.

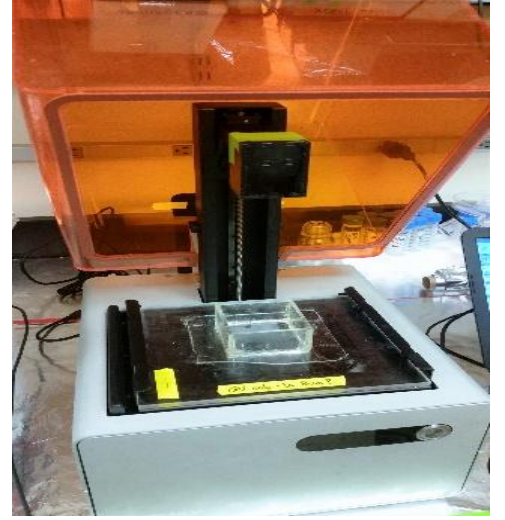

(a)

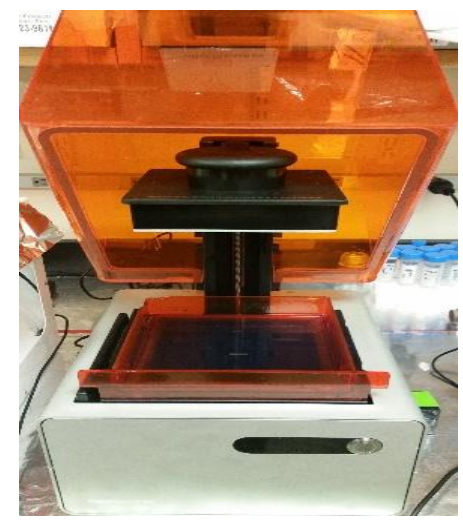

(b)

Şekil 6. a) Formlab Form 1+ 3B Yazıcı orijinal tasarım, b) Biyo yazıcı olarak yeniden uyarlanmış tasarlanmış

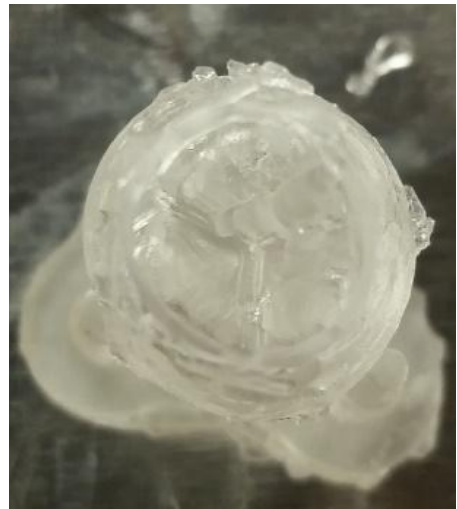

(a)

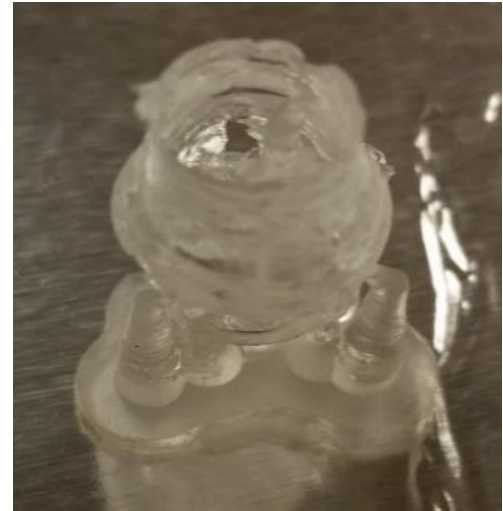

(b)

Şekil 7 Triküspit kalp kapakçığı, a) Yukarıdan görünüş b) Önden görünüş

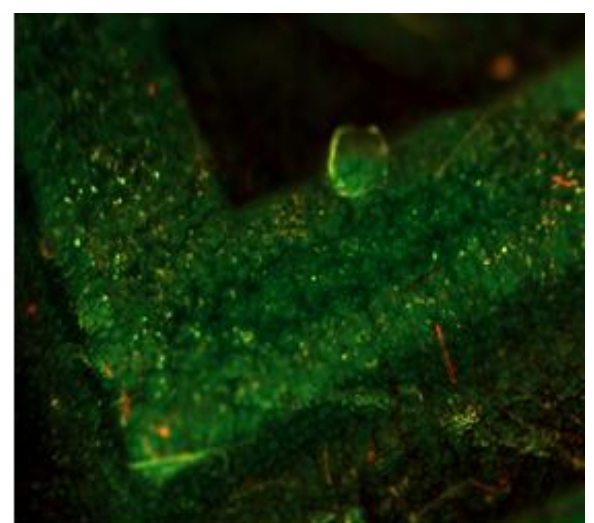

(a)

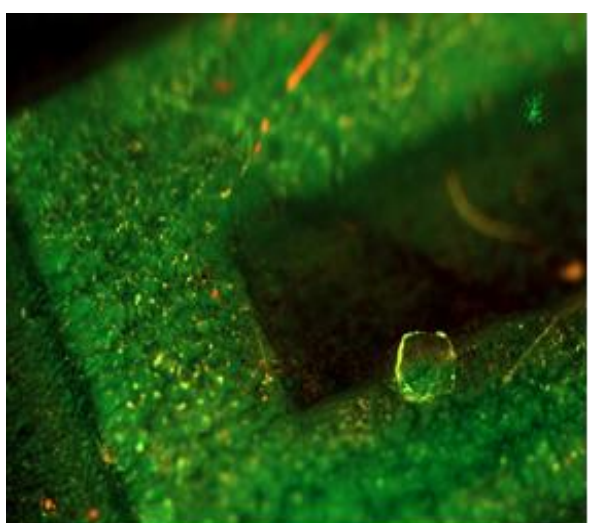

(b)

Şekil 8: Ters Mikroskop ile elde edilmiş kalp kapakçıkları üzerine ekilmiş kardiyak fibroblast hücreleri arasındaki canlı ve ölü hücreler 
Üretilen yapı genel olarak başarılıdır ve stereolitografi sisteminin yüksek hassasiyetini ve başarısını kanıtlamaktadır.

Şekil 7'de gösterilen triküspit kalp kapakçı̆̆ında PEGDA (Polyethylene Glycol Diacrylate: Type A: $\mathrm{M}_{\mathrm{n}}$ 7009) kullanılmıştır. En önemli sorun kan akışının geçişi için gerekli olan boşluk oluşturulamamıștır. Bu üretim sonrasında çeșitli kesiciler aracılığı ile oluşturulmuştur.

\subsection{Hücre canlılığı testleri}

Şekil 8'de ters mikroskop ile kalp kapakçıklarından alınmış görüntülere yer verilmiştir. Canlı hücreler yeșil, ölü hücreler ise kırmızıdır. Resimhğcre kültürünün üçüncü gününe aittir. Resim üzerinde yapılan analize göre üçüncü gün için $\% 70$ hücre canlılı̆̆ı gözlemlenmiştir.

$\mathrm{Bu}$ oran literatürde yer alan mikro ekstrüksiyon metodu ile üretilen yapay kalp kapakçılkları ile kıyaslandı̆̆ında oldukça yeterli görülmektedir. Bu testlerde de aynı süreler için yapılan hücre canlılığı testlerinde \%80 civarında hücre canlılığı gözlendiği rapor edilmiştir [10-14].

\section{Tartışma ve Sonuç}

Çalışmada karşılaşılan en ciddi sorun baskı esnasında karşımıza çıkan üretime dair yapısal hatalardır. Özellikle biyouyumluluğu yüksek olan malzemeler stereolitografinin şiddeti düşük olan ultraviole ışını altında yeteri kadar sertleșememekte, bu nedenle de yapısal bütünlügünü yeteri kadar koruyamamaktadır. $\mathrm{Bu}$ sorun temel olarak kan akışının geçmesi için gerekli olan boşluğun üretilememesi gibi bazı sorunlar yaratmaktadır. Ancak bu sorun da üretilen kalp kapakçı̆̆ında çeşitli kesiciler yardımıyla ihtiyaç duyulan boşluğun oluşturulması ile aşılmıștır. Yine de süreç kusursuzlaştırmak üzere optimize edilmelidir.

$\mathrm{Bu}$ çalışmadaki temel strateji stereolitografi metodu ile yapısal bütünlüğe sahip biyouyumluluğu olan triküspit kalp kapakçıkları üretmekti. Gelecek çalışmalar olarak; üretilmiş olan bu yapay kalp kapakçıklarında biyomekanik testler gerçekleştirilebilir. Çekme ve gerilme testleri, esneme testleri gerçekleştirilebilinir. Elde edilecek olan sonuçlar biyoprostetik kalp kapakçılarının biyomekanik sonuçları ile kıyaslanabilir ve böylelikle üretim süreçleri zaman içerisinde tekrar tekrar optimize edilerek çalışma geliştirilebilir.

Bundan başka dört boyutlu yazıcı teknolojilerinin gelişmesine bağlı olarak üç boyutlu yazıcı sistemlerinden sonra dört boyutlu yazıcı sistemlerinin de yapay kalp kapakçığı fabrikasyonu çalışmalarında kullanılması da mümkün görülmektedir [15-16].
Son olarak bu çalışma ülkemizde henüz yeni yeni güçlenmekte olan biyoteknoloji ve biyomedikal mühendisliği çalışmalarının güçlenmesi açısından bir adım teşkil edecek, pek çok çalışmaya öncülük edecektir [17-32].

\section{Kaynakça}

[1] US Dep. Health Hum. Serv. 2014. The need is real: data. Donate the gifts of life statistics and figures. US Dep. Health Hum. Serv., Washington, D.C.

[2] Driessen, J.V.C., Mol, A., Bouten, C.V.C, Baaijens, F.P.T. 2007. Modeling the mechanics of tissue engineered human heart valve leaflets. J. Biomech. 40 (2007), 325-334.

[3] Balguid, A., Rubbens, M.P., Mol, A., Bank, R.A., Bogers, A., Van Kats, J.P., De Mol, B., Baaijens, F.P.T., Bouten, C.V.C., 2007. The role of collagen cross links in biomechanical behaviour of human aortic heart valve leaflets - relevance for tissue engineering. Tissue Eng, 13(2007), 1501-1511.

[4] Engelmayr, G.C., Rabkin, E., Sutherland, F.W.H., Schoen, F.J., Mayer, J.E., Sacks, M.S. 2005. The independent role of cylic flexure in the early in vitro development of an engineered heart valve tissue. Biomaterials, 26(2005), 175-187.

[5] Sodian, R., Hoerstrup, S.P., Sperling, J.S., Daebritz, S., Martin, D.P., Moran, A.M., Kim, B.S., Schoen, F.J., Vacanti, J.P., Mayer, J.E., 2000a. Early in vivo experience with tissue engineered trileaflet heart valves. Circulation, 102(2000), 22-29.

[6] Hoerstrup, S.P., Sodian, R., Daebritz, S., Wang, J., Bacha, E.A., Martin, D.P., Moran, A.M., Guleserian, K.J., Sperling, J.S., Kaushal, S., Vacanti, J.P., Schoen, F.J., Mayer, J.E. 2000. Functional living trileafet heart valves grown in vitro. Circulation 102(2000), 44-49.

[7] Bajaj, P., Schweller, R.M., Khademhosseini, A., West, J.L., Bashir, R. 2014. 3D biofabrication strategies for tissue engineering and regenerative medicine. Annu. Rev. Biomed. Eng., 16(2014), 247-276.

[8] Sodian, R., Loebe, M., Hein, A., Martin, D.P., Hoerstrup, S. 2002. Application of stereolithography for scaffold fabrication for tissue engineered heart valves. ASAIO Journal 48(2002), 12-16.

[9] Hosseini, V., Ahadian, S., Ostrovidov, S., CamciUnal, G., Chen, S., Kaji, H., Khademhosseini, A. 2012. Engineered contractile skeletal muscle tissue on a microgrooved methacrylated gelatin substrate, Tissue Engineering Part A, 18(23-24), 2453-2465

[10] Hockaday, L.A., Kang, K.H., Colangelo, N.W, Cheung, P.Y.C., Duan, B., Malone, E., Wu, J., Girardi, L.N., Bonassar, J.L., Lipson, H. 2012. Rapid 3D printing of anatomically accurate and 
mechanically heterogeneous aortic valve hydrogel scaffolds. Biofabrication 4(3), 035005

[11] Duan, B., Hockaday, L.A., Kang, K.H., Butcher, J.T. 2013a. 3D Bioprinting of heterogeneous aortic valve conduits with alginate/gelatin hydrogels, J. Biomed. Mat. Research Part A, 101A(5), 12551264

[12] Duan, B., Hockaday, L.A., Kapetanovic, E., Kang, K.H., Butcher, J.T., 2013b, Stiffness and adhesivity control aortic valve interstitial cell behavior within hyaluronic acid based hydrogels. Acta Biomaterialia, 9(8), 7640-7650

[13] Duan, B., Kapetanovic, E., Hockaday, L.A., Butcher, J.T. 2014. Three-dimensional printed trileaflet valve conduits using biological hydrogels and human valve interstitial cells. Acta Biomaterialia, 10(5), 1836-1846

[14] Chang, C., Boland, E.D., Williams, S.K., Hoying, J.B. 2011. Direct-write bioprinting threedimensional biohybrid systems for future regenerative therapies. Journal of Biomedical Materials Research, 98B(1), 160-170

[15] Li, Y.C., Zhang, Y.S., Akpek, A., Shin, S.R., Khademhosseini, A., 2016, 4D bioprinting: the next-generation technology for biofabrication enabled by stimuli-responsive materials, Biofabrication, 9(2016), 012001

[16] Akpek, A., Zhang, Y.S., Khademhosseini, A. 2016, Three Dimensional (3D) Bioprinting of Stereolithography Applied Tissue Engineered Artifical Heart Valves, The Proceedings of XX. National Biomedical Engineering Congress, 1-3 Aralık, İzmir, 45 - 49

[17] Öztarhan, A., Akpek, A., Oks, E., Nikolaev, A. 2010. Modifying medical textiles with antibacterial and friction resistance abilities by an alternative nanotextile technology called ion implantation technique. $15^{\text {th }}$ National Biomedical Engineering Meeting, 21-24 April, Antalya, 43-48

[18] Nikolaev, A.G., Yushkov, G.Yu, Oks, E.M., Oztarhan, A., Akpek, A., Hames Kocabas, E., Urkac, E.S., Brown I.G. 2014. Modification of antibacterial surface properties of textile polymers by vacuum arc ion source implantation. Applied Surface Science, 310(2014), 51-55.

[19] Akpek, A. Youn, C., Kagawa, T. 2013. Temperature measurement control problem of vibrational viscometers considering heat generation and heat transfer effect of oscillators. 9th Asian Control Conference, 23-26 June, 1-6.

[20] Akpek, A., Youn, C., Maeda, A., Fujisawa, N., Kagawa, T. 2014. Effect of thermal convection on viscosity measurement in vibrational viscometer. Journal of Flow Control, Measurement \& Visualization, 2(2014), 12-17

[21] Akpek, A., Youn, C., Kagawa, T. 2014. A study on vibrational viscometers considering temperature distribution effect. Transactions of the Japan Fluid Power System Society, 45.3, 2936.

[22] Liu, W., Heinrich, M.A., Zhou, Y. Akpek, A., Hu, N., Liu, X., Guan, X., Zhong, Z., Jin, X., Khademhosseini, A., Zhang, Y.S. 2017. Extrusion Bioprinting of Shear-Thinning Gelatin Methacryloyl Bioinks. Advanced Healthcare Materials, 6(12), 1601451.

[23] Sari, S., Akpek, A. 2016. Ortam Sicaklığının Ultrasonik Nebülizatörler Üzerindeki Etkinliğini Ölçen Sistem Tasarımı. Electrical, Electronics and Biomedical Engineering National Conference, 1-3 December, Bursa, 521-525.

[24] Uçar, T., Koçak, O., Akpek, A. 2016. New concept design of an insulin pen for visually impaired or blind diabetius mellitus patients. Medical Technologies National Congress, 27-29 October, Antalya, 1-4.

[25] Altınsu, B., Koçak, O., Akpek, A. 2016. Design and analysis of an autoclave simulation using MATLAB/Simulink. Medical Technologies National Congress, 27-29 October, Antalya, 1-4.

[26] Koçak, O., Kurtuldu, H., Akpek, A., Koçoğlu, A., Eroğlu, 0. 2016. A medical waste management model for public private partnership hospitals. Medical Technologies National Congress, 27-29 October, Antalya, 1-4.

[27] Akpek, A. 2016. Effect of non-uniform temperature field in viscosity measurement. Journal of Visualization, 19.2 (2016), 291-299.

[28] Çiftçioğlu, Ç., Koçak, O., Akpek, A. 2015. Remote control of centrifuge and injection systems via MATLAB and ARDUINO, Medical Technologies National Conference,15-18 October, Bodrum, 1-4

[29] Cebeci, S.A., Çiftçioğlu Ç., Koçak, O., Akpek, A. 2015, Electronic Pillbox Design for Demantia Patients, Medical Technologies National Conference, 15-18 October, Bodrum, 1-3.

[30] Avci, H., Güzel, F.D., Erol, S., Akpek, A. 2017. Recent advances in organ-on-a-chip technologies and future challenges: A Review. Turkish Journal of Chemistry. DOI: 10.3906/kim-1611-35

[31] Koçak, O., Gürel, E., Akpek, A., Koçoğlu, A., 2015 Control of Wheel Chair for Quadriplegia Patients: Design A Bioremotecontrol. 9th International Conference On Electrical and Electronics Engineering, 26-28 November, Bursa, 1-5

[32] Akpek, A. 2017. Effect of Ambient Temperature Variations on Particle Dimesions in Ultrasonic Nebulizers during Cold Vaporization. Adv. Sci. Technol. Eng. Syst. J. 2(3), 946-950 